\title{
De la ley divina a la ley bumana: Alfonso de Castro (1495-1558) $y$ el Nuevo Mundo
}

From the Divine Law to the Human Law: Alfonso de Castro (1495-1558) and the New World

Verónica Murillo Gallegos

Universidad Autónoma de Zacatecas, México veramurillog@uaz.edu.mx

DOI: https://doi.org/10.15366/bp2021.26.005

Bajo Palabra. II Época. No26. Pgs: 107-122 
Recibido: 10-10-2020

Aceptado: 30-10-2020

\section{Resumen}

Alfonso de Castro en su obra De potestate legis poenalis (1550) define la ley como producto de la voluntad y señala que su interés es la ley humana; sin embargo, en su teoría, la ley divina tiene un papel fundamental. En este trabajo describiremos la equivalencia que Castro establece entre la ley natural y la ley divina para analizar cómo deriva la ley humana de ellas. El objetivo es mostrar las implicaciones del concepto de ley como precepto de la voluntad en las polémicas surgidas en torno al descubrimiento y dominio del Nuevo Mundo, particularmente entre los misioneros franciscanos en Nueva España.

\section{Abstract}

Alfonso de Castro's De potestate legis poenalis (1550) defines the law as a product of the Will and states that his interest is human law; however, in his theory of justice, the divine law has a fundamental role. In this article, we'll describe the equivalence that Castro stablishes between natural law and divine law to analyze how the human law derives from them. The aim is to show the implications of the concept of law as precept of Will in the controversies that arose around the discovery and domination of the New World, mostly among Franciscan missionaries in New Spain.
Palabras clave: Alfonso de Castro, ley divina, ley natural, ley humana, Nuevo Mundo.
Keywords: Alfonso de Castro, divine law, natural law, human law, New World. 


\section{Introducción}

El concepto de ley es Clave en las polémicas sobre el Nuevo Mundo, pues con él fueron evaluadas las culturas prehispánicas, se demandaron derechos de dominio sobre las conquistas y se proyectaron formas de interacción social y política en las colonias americanas. Este concepto fundamental, sin embargo, tiene por lo menos dos acepciones en el siglo XVI: ley como el orden surgido de una inteligencia y ley como mandato producido por una voluntad. Los investigadores contemporáneos ${ }^{1}$ han privilegiado el estudio de la primera acepción de ley y se han centrado mayormente en el papel de la ley natural dentro de problemas como la guerra a los indígenas, el dominio de los europeos sobre América, la racionalidad del indio, etc., destacando por lo general la obra de la Escuela de Salamanca, explorando su fuente fundamental, Tomas de Aquino, y atendiendo a los autores más conocidos de la época: Francisco de Vitoria, Domingo de Soto, Bartolomé de las Casas y Alonso de la Veracruz.

Si revisamos algunas de estas disputas, conviene notar que todos los que se pronunciaron sobre estos temas coinciden en tomar como título justo de guerra o de dominio algo relacionado con la religión cristiana: ya bajo la forma de derecho a predicar el evangelio (ius communicationis), ya como la obligación que se tiene de dar a conocer la verdad (el cristianismo) a quién la desconoce, ya como remedio para evitar que se siguieran cometiendo pecados e injusticias (muchos de ellos relacionados con la religiosidad indígena) entre los pueblos americanos. También es común que se establezcan analogías entre los indígenas americanos y los gentiles de la antigüedad -o los judíos o los moros o incluso los herejes de la época- por lo que no pocas veces se aplicó a la problemática americana la legislación que en otros momentos y lugares se dispuso para todos aquellos que se encontraban al margen de la cristiandad. Por eso es pertinente analizar el tema de la ley divina en los autores de la época y sus relaciones con la problemática del Nuevo Mundo.

Nos proponemos atender a la segunda acepción de ley en la obra de Alfonso de Castro, franciscano nacido en Zamora, profesor en Salamanca, padre del derecho

\footnotetext{
${ }^{1}$ Entre otros: Silvio Zavala, José María Gallegos Rocafull, Juan Carlos Torchia Estrada, Anthony Pagden, Carmen Rovira y Mauricio Beuchot.
} 
penal por su obra De potestate legis poenalis (Salamanca, 1550), teólogo del Concilio de Trento, autor fundamental sobre el tema de la herejía con su Adversus omnes haereses (París, 1534) y su De iusta haereticorum punitione (Salamanca, 1547)2 , quien además se ocupó directamente de algunas cuestiones americanas. Aunque este autor es referido por varios personajes que escribieron desde la Nueva Espańa, es difícil demostrar que hubo una influencia de Castro en ellos, porque la mayoría de esos autores no hace tratados sino crónicas y distintos textos para apoyo de la evangelización de los indígenas; no obstante, podemos hablar de una importante concordancia en algunos de sus planteamientos, pues muchos misioneros novohispanos, sobre todo franciscanos, hablan de sus experiencias en América usando conceptos acordes con las posturas de Castro: una concepción de ley como producto de la voluntad, cierta confusión o equivalencia entre la ley natural y la ley divina y una particular apreciación de los nativos americanos.

En este trabajo centraremos nuestra atención en la obra De potestatis legis poenalis para señalar primero algunas cuestiones sobre la voluntad y sobre la identificación que hace Castro entre la ley natural y la ley divina. Después pasaremos a explicar con detalle cómo es que las leyes humanas derivan de la ley natural-divina en la propuesta del zamorense y sus implicaciones. Por último, apuntaremos algunas valoraciones de Castro sobre el Nuevo mundo en su Parecer sobre la educación de los indígenas $(1543)^{3}$ y en De iusta haereticorum punitione; terminaremos mostrando la concordancia de estos planteamientos con la tradición franciscana contenida en los escritos de los misioneros que laboraron en Nueva Espańa.

\section{Cuestiones preliminares: ley natural, ley divina y voluntad}

Cuando Castro define a la ley como "la recta voluntad de aquel que representa al pueblo, promulgada por voz o por escrito con la intención de obligar a los súbditos a obedecerla" ${ }^{4}$, afirma su postura de que la ley es fruto de la voluntad y deja

\footnotetext{
${ }^{2}$ Cfr. Manuel Castro, "Fray Alfonso de Castro OFM (1495-1558), consejero de Carlos V y de Felipe II", Salmanticensis, 6 (1958), pp. 281-322. Consignamos solamente las fechas de las primeras ediciones, pues del Adversus, por ejemplo, hay veinte impresiones solamente entre 1534 y 1568.

3 Alfonso de Castro, Si a los hombres del Orbe Nuevo a los que el vulgo llama indios [...] sea conveniente instruirlos en las Artes que llaman Liberales y enseñarles la Sagrada Teología y revelarles todos los Misterios de nuestra Fe (1543), en Ignacio Osorio Romero, La enseñanza del latín a los indios, México, Universidad Nacional Autónoma de México, 1990, 35-60.

${ }^{4}$ Seguimos la edición Fratris Alfonsi A Castro, De potestate legis poenalis libri duo, Lugduni, Haeredes Iacobi Iuntae, MDLVI. La cita completa correspondiente al texto citado está en Lib. $1^{\circ}$, cap. 1, p. 5: Lex est recta voluntas eius, qui vicem populi gerit, voce aut scripto promulgata, cum intentione obligandi subditos ad parendum illi. Traducción propia.
} 
en claro que su interés es la ley humana, la ley penal en particular, como está en el título de su libro. Sin embargo, la ley divina en la obra De potestati legis poenalis de Castro es fundamental por tres razones: la primera porque desde las primeras líneas de su trabajo afirma que "la potestad de las leyes humanas depende de la ley divina" 5; la segunda, porque si bien señala que la ley natural es la raíz de todas las leyes, argumenta también en torno a las palabras de san Pablo afirmando que ley natural es ley de Dios ${ }^{6}$; y en tercer lugar porque su objetivo principal es demostrar que algunas leyes humanas obligan en conciencia bajo pena de pecado mortal, frente a quienes consideran que la única ley que obliga de esa manera es la ley divina ${ }^{7}$. Estos tres planteamientos, como gran parte de la argumentación del autor, giran en torno a la afirmación de que la ley divina es la misma que la ley natural y que ambas consisten en los preceptos del Decálogo.

Es sabido que la mayoría de los escolásticos proponen la primacía de la ley natural sobre la ley humana y además afirman que ésta deriva de aquella como de su principio; de hecho, que la ley humana sea justa depende de que mantenga una relación estrecha con la ley natural, por más que ella deba conformarse al contexto en que se instituye. También nuestro autor acepta esto, pero la derivación de la ley natural a la ley humana debe ser analizada cuidadosamente ya que hay un diferencia importante en atribuir tal derivación a la razón que atribuirla a la voluntad ${ }^{8}$. La explicación de Castro sobre esta derivación podría resultar un tanto confusa por la cantidad de temas que involucra el contexto donde la ofrece: al examinar una definición de ley dada por Cicerón en De legibus, "Ley es la suma razón ínsita en la naturaleza, la cual ordena lo que se debe hacer y prohíbe lo contrario", el franciscano se opone a él argumentando que la ley no es obra del intelecto sino de la voluntad y después señala que esa definición conviene solamente a la ley natural, porque es la única que está ínsita en la naturaleza ya que, señala Castro, si toda ley estuviera ínsita en la naturaleza ninguna podría mutar ni ser justamente abrogada y por experiencia sabemos que las leyes humanas cambian con el tiempo y las circunstancias.

5 Ibid, Nuncupatoria: Aut quis etiam dubitat legum humanarum potestatem a diuina lege adeo pendere, vt si illa cum diuina lege pugnent, nullam potestatem, nullumque prorsus robur habere possint?

${ }^{6}$ Castro argumenta que la ley natural es ley divina en Ibid, Lib. $1^{\circ}$, cap. IV; pero a lo largo de todo el libro reitera esta equivalencia con distintas frases.

7 Tema central del De potestate legis considerado en el lib. $1^{\circ}$, cap. IV.

${ }^{8}$ Manuel Lázaro Pulido, "Una reflexión sobre la tradición y modernidad en Alfonso de Castro a propósito de la ley”, Cauriensia, vol. XIII (2018), p. 459-478, advierte que para Castro no hay una relación de derivación ni de participación entre la ley natural y la ley humana, precisamente por el acento puesto en la voluntad; sin embargo, como veremos, Castro usa los términos "derivación” y "causa” para describir esta relación, por lo que se hace necesaria una explicación más detallada. 
Sin embargo, en excusa de Cicerón, el franciscano comenta que "toda ley está ínsita en la naturaleza porque en la misma naturaleza están ínsitos los principios de la ley natural, de los cuales todo el resto de las leyes derivan, aunque no todas por el mismo modo se deducen de los principios" surgen ante esta afirmación. La primera tiene que ver con la manera en que Castro concibe la voluntad pues, aunque insiste en que la ley no es obra del intelecto sino de la voluntad, señala que "en cierto modo la voluntad pertenece a la razón y es una parte de ella" ${ }^{10} ;$ y líneas más adelante dice que tal definición ciceroniana solo conviene a la ley natural porque es ella la que está inscrita en los corazones, de tal manera que "los hombres naturalmente consideran hacer aquellas cosas que son de ley porque por persuasión de la razón natural, sin ningún otro guía, entienden que valen aquellas cosas que la ley previene en el Decálogo" ${ }^{11}$, con lo que parecería que no hay gran diferencia en que las leyes sean producto de la voluntad o del intelecto ${ }^{12}$. El segundo problema es que Castro afirma que el Decálogo es de ley natural $y$, en esta parte, todavía no ha identificado abiertamente a la ley natural con la ley divina (lo hace en el capítulo IV), si bien ya ha pasado revista a varias características de la ley y no pocas veces ha atribuido casi indistintamente las mismas cualidades a la ley natural y a la ley divina.

Podemos aclarar un poco estos problemas atendiendo a otras partes de la obra de Castro. La única diferencia que él establece entre la ley natural y la ley divina es que ésta es revelada por Dios a los hombres mientras que aquella es donación de la naturaleza y está en las criaturas desde su creación. En este sentido, el Decálogo es de ley divina más que de ley natural. Sin embargo, el autor señala después que ambas leyes fueron dadas por Dios, por eso son la misma, y poco importa si a una la dio a conocer a los hombres por revelación y a la otra por donación de la naturaleza ${ }^{13}$; esto es, el autor reconoce una diferencia entre ellas, pero no la considera

${ }_{9}$ Castro, De potestate, Lib. 1º, cap. II, p. 23-24: Sed in excusationem Ciceronis dici posset omnem legem esse insitam in natura: propterea quod in ipsa natura sunt insita principia legis naturalis, a quibus reliquae omnes leges derivantur, quamuis non omnes eodem modo ab illis principiis deducuntur.

${ }^{10}$ Ibid, p. 22: Secundo peccat illa definitio, quia etsi daremus voluntatem quodammodo ad rationem pertinere, o partem aliquam illius esse, adhuc definitio illa non esset bona, quia non omni legi, sed soli legi naturali conuenit.

11 Idem: Haec est enim illa lex, quam Paulus in ea, quae est ad Romanos epistola, dicit esse scriptam in cordibus hominum, ac proinde homines naturaliter ea, quae legis sunt, facere censet: quia naturali ratione suadente, sine aliquo alio praeceptore intelligere valent ea, quae lex in Decalogo praecipit.

12 Concordamos con Sebastián Contreras Aguirre, "Voluntarism in the early Modern Period? Alphonsus de Castro and his philosophy of law", Acta Philosophica, 2 (2020), cuando seńala que no hay voluntarismo en Castro porque no le concede autonomía absoluta a la voluntad, sino que ésta debe conformarse con la razón. No obstante, considero que tampoco tiene las mismas consecuencias que la ley derive por medio del intelecto a que derive mediante la voluntad.

${ }^{13}$ Castro, De potestate, Lib. 1, cap. IV, p. 46: Nam cum constet naturalem legem dari a Deo, qui est conditor naturae, parum referre mihi videtur, quod hoc aut illo modo detur ab eo, videlicet per reuelationem, aut per naturae 
determinante como para diferenciarlas. Lo importante para Castro es que ambas son leyes prescritas por Dios, esto es: su origen en la voluntad divina, y no la manera en que llegan a ser conocidas por el hombre. Por eso Castro evalúa también las leyes de los antiguos romanos según su concordancia con esta ley divina, pese a que ellos no tuvieron noticia del Evangelio ${ }^{14}$; en cuyo caso, que es también el de los indígenas americanos, seguir los dos primeros preceptos del Decálogo es prácticamente imposible.

Esto nos orienta a considerar que no tiene las mismas implicaciones decir que las leyes humanas derivan de la natural-divina mediante la voluntad que afirmar que derivan gracias a la razón. En la concepción de la ley como fruto de la voluntad no hay tendencia natural que fundamente el obrar moral como sucede, por ejemplo, en la propuesta de Tomás de Aquino cuando habla de la inclinación natural a hacer algo ${ }^{15}$. Aseverar que la ley es mandato es asumir que la sede original de la justicia es la voluntad divina, a cuya ley está obligada toda la creación. Por eso, en la propuesta de nuestro autor, la potestad de las leyes humanas está en su concordancia con la ley divina, por eso derivan de la ley natural que es la misma que la ley divina: el Decálogo. La cuestión es considerar cómo se realiza esa derivación para determinar también cual es el nexo que existe entre la ley humana y la ley divina-natural.

\section{Las leyes humanas se derivan de la ley natural y divina}

Debido a Que Castro identifica a la Ley natural con la divina -y aunque en la parte que procedemos a analizar explica que las leyes humanas derivan de la ley natural-se puede decir, sin traicionar al autor, que las leyes humanas derivan de la ley divina. Esto además concuerda con otras afirmaciones del autor a lo largo del De potestate, entre ellas la tesis central: que la potestad de las leyes humanas depende de la ley divina. De aquí nuestra decisión de poner, para referir esta

\footnotetext{
donationem.

${ }^{14}$ Ibid, Lib. $1^{\circ}$, cap. II, p. 31: Nam quod rerum diuinarum notitia sit legislatori summe necesaria, vt iustam legem condere possit, vel ex hoc aperte conuincitur, quod aliquae sunt leges iniustae \& pessimae, a Romanis Imperatoribus aeditae, ob solam ignorantiam legis diuinae, quam si bene (vt oportebat) intellexissent, nunquam tales leges condidissent.

15 Ocuparía mucho espacio exponer la propuesta del Aquinate, para quien la ley es producto de la razón, y establecer detalladamente un contraste entre ambas posturas. Ver Juan Cruz Cruz, Cuestiones disputadas del Siglo de Oro, EUNSA, Pamplona, 2009, cap. 2, pp. 43 y ss., donde además de exponer algunas cuestiones esenciales sobre la ley en Tomás de Aquino, profundiza sobre la desconexión entre la naturaleza y la moral en las propuestas de Duns Escoto y Guillermo de Ockham, quienes afirman que la ley es producto de la voluntad. Castro no cita a ninguno de estos dos franciscanos en el tema que ahora consideramos, aun cuando comparte con ellos la parte fundamental: una concepción de ley como mandato.
} 
equivalencia, "ley natural-divina". Procedemos entonces a analizar su argumento sobre tal derivación.

Según Castro, las leyes humanas derivan de la ley natural-divina, de dos maneras diferentes ${ }^{16}$. Según la primera forma de derivación, algunas se deducen de los principios de la ley natural como efecto necesario de una causa producida naturalmente, asi como las conclusiones se producen de los principios por medio de una buena consecuencia ${ }^{17}$. Esto fácilmente nos lleva a pensar en una derivación obtenida mediante la razón, cuando de unos principios se obtienen, lógicamente, las conclusiones correspondientes; o bien podemos pensar en cierto necesitarismo por el cual de una causa (eficiente) surge de manera natural un efecto, sin intervención de voluntad alguna, como en una especie de inercia; no obstante, notemos que más parecería una explicación por analogía que directa y literal: tamquam effectus necessario a causa naturali producti, sicut conclusiones producuntur a principiis per medium bonae consequentiae. Castro ilustra esta forma de derivación con un ejemplo: del precepto natural general "lo que no quieras para ti, no lo hagas a otro", se sigue el precepto del Decálogo "está prohibido robar" y de éste, a su vez, la prohibición de la usura.

Si interpretamos las palabras de Castro como un símil, debemos decir que no hay estrictamente una derivación lógica ni alguna necesidad natural en el paso de un principio general natural a una ley positiva pero sí una semejanza considerable entre ellos. Sin embargo, no podemos afirmar esto de manera contundente cuando Castro precisa que estas leyes deben decirse más verdaderamente naturales que humanas, porque nada reciben de la voluntad humana, sino que todo su vigor viene de la misma naturaleza. Lo que queda claro, a partir de esto, es que la ley humana debe provenir de la voluntad humana y que estos principios generales provienen más directamente de la voluntad divina que originalmente los prescribió, no importa si los dio a conocer con la creación a la naturaleza o mediante las tablas de la ley a Moisés. En este sentido, se entendería que los preceptos más próximos a la ley natural-divina no requieren de la voluntad humana para ser instituidos ${ }^{18}$, sino de la sola voluntad divina que los estableció. En este caso, es el "ingenio humano" el que las explica y extrae de los principios naturales, mientras que la voluntad humana

\footnotetext{
${ }_{16}$ Expongo aquí la argumentación contenida en Castro, De potestate, lib. 1\%, cap. II, pp. 23-25.

${ }_{17}$ Ibid, Lib. $1^{\circ}$, cap. II, p. 24: Aliae sunt, quae a principiis legis naturalis deducuntur, tanquam effectus necesario a causa naturali producti: sicut conclusiones producuntur a principiis per medium bonae consequentiae.

${ }^{18}$ Esta primera forma de derivación justificaría la postura de Sebastián Contreras, op. cit., ya que, aunque la ley humana sea producto de la voluntad del legislador, no se trata de una voluntad autosuficiente, sino de una que tiene límites bien definidos: debe ajustarse a las circunstancias en que se instituye la ley, requiere de un proceso contingente y prudencial y debe reproducir en la ley humana, de alguna manera, al principio general natural del que parte, etc.
} 
se reduciría a la obediencia ya que, según Castro, son leyes que aunque ningún hombre las hubiera redactado, obligan con fuerza plena debido a su origen y a su cercanía con él ${ }^{19}$.

De acuerdo con la segunda forma, otras leyes humanas se derivan de la ley natural por modo de especificación o determinación, así como, en cierto modo, las especies en las cosas artificiales se derivan del género; en cuya deducción, aunque haya una necesidad por la cual el artífice instituye operando cierta especie, sin embargo, la instituye por la mera voluntad que depende del artífice ${ }^{20}$. El ejemplo que acompaña este modo de derivación consiste en las leyes que instituyen una recompensa para una virtud o una pena para un vicio, las cuales no pueden ser deducidas del principio general natural ya que, aunque es necesario por ley natural que se dé un premio a la virtud o un castigo al vicio, de esto no se sigue que tal premio -o castigo- específico corresponda a tal acción concreta; esto último es determinado por el legislador. Para Castro estas leyes verdaderamente se dicen humanas porque dependen de la voluntad de los hombres.

Notemos que aquí es la voluntad humana la que elige concretar un principio tan general como "el vicio merece un castigo" en algo como "quien cometa fraude debe ser encarcelado". Es la voluntad del legislador humano la que asigna una pena concreta, y no otra, a un delito concreto ya que, por ejemplo, como castigo a la embriaguez puede lo mismo prescribirse una multa o prisión o trabajo social, pero sólo el legislador elige, entre estas y otras posibilidades, una pena y decide su intensidad.

Aquí se ven con mayor nitidez las consecuencias de que la derivación sea por medio de la voluntad humana: el artífice, un artesano o un artista, tienen una idea general o ciertos principios generales de lo que es una mesa o un cuadro y cómo hacerlo, pero es completamente su elección hacerlo de un cierto material, figura, tamaño, color o textura; no hay aquí ninguna relación entre el principio general y el producto particular más allá de las semejanzas que el artífice quiera conservar entre ellos ${ }^{21}$. Esto implica, ciertamente, que un legislador puede instituir una ley incluso sin atender a los principios generales de ley natural-divina,

${ }^{19}$ Castro, De potestate, Lib. $1^{\circ}$, cap. II, p. 24: Nam omni legislatoris humana voluntate seclusa, ita vt nullus vnquam homo de illis aliquid statuisset, nihilominus illae plenam suam vim ad obligandum haberent.

${ }^{20}$ Idem: Aliae sunt leges humanae, quae a lege natural deriuantur per modum specificationis aut determinationis: sicut species in rebus artificialibus quodammodo deriuantur a genere. In qua deductione, licet sit necessitas, qua aliquam certam speciem statuat artifex in operando: quod tamen hanc aut illam statuat, ex mera artificis pendet voluntate.

${ }^{21}$ Esto explica que Manuel Lázaro, op. cit, señale que Castro no establece entre las leyes ninguna relación de derivación ni de participación, como sí la hay, por ejemplo, en la propuesta del Aquinate. Con esto también se entiende que Juan Cruz, op. cit., señale que hay una desconexión entre la naturaleza y la moral en una acepción de ley como producto de la voluntad. 
pero bien se cuida Castro de caer en este extremo cuando señala que la ley humana no sería justa si se separara completamente de la ley natural, aunque nada prescribiera fuera de ésta ${ }^{22}$. Y Castro, como la gran mayoría de los escolásticos, afirman que una ley injusta ni siquiera merece el nombre de "ley". Si bien el zamorense propone que estas leyes dependen completamente de la voluntad humana, no deja de limitar a ésta obligándola a seguir la ley natural-divina hasta tal punto que propone que estas leyes, las del segundo modo de derivación, también pueden llamarse naturales por extensión del significado del término, porque en ellas se discierne (discernitur), como el género en la especie, lo que la ley natural ordena hacer.

No obstante, debemos señalar que esto último obedece al objetivo principal del De potestate: la potestad de la ley penal. Castro dice que estas leyes dependen de la voluntad humana pero, para tener poder de obligar a alguien, eso no es suficiente: deben tener "similitud" con la ley natural-divina de la cual derivan ${ }^{23}$; lo que, en esta manera de derivación, significa que el legislador humano debe elegir conservar en sus leyes cierta semejanza con la ley natural-divina, debe querer obedecer la ley natural-divina con su ley positiva; en otras palabras, esa semejanza es una elección del legislador y no algo que él haga por algún condicionamiento natural, por inclinación, o por la fuerza de algún razonamiento lógico que lo obligue a concluir una ley positiva a partir de algún principio de ley natural-divina ${ }^{24}$. Con esto cobra sentido la afirmación de Castro de que si alguna ley humana prescribiera o prohibiera algo contra la ley divina, nadie estaría obligado a obedecerla ${ }^{25} \ldots$ y eso aplica incluso para quienes desconocen el Evangelio.

22 Castro, De potestate, Lib. 1o, cap. II,p. 24: Si enim lex humana omnino a lege naturali discederet, illa iusta non esset, etsi nihil extra legem naturalem praeciperet...

${ }^{23}$ Además de otras características que plantea a lo largo del cap. I del primer libro, cuando explica detenidamente su definición de ley, como el de que sea instituida por quien tiene verdadera potestad sobre el pueblo (no por cualquier particular) y que sea promulgada por voz o por escrito.

${ }^{24}$ En todo caso, la razón interviene cuando se piensan las mejores opciones de cara a las circunstancias en las que, y para las cuales, se instituye una ley; pero se requiere el acto de la voluntad para elegir una opción y sobre todo para emitir esa opción mandando o prohibiendo algo. De ahí que Castro reitere que no tiene vigor de ley aquello que el príncipe inventó o ha entendido bien, sino lo que le place. Remito al lib. 1º, cap. 1, p. 6-8 del De potestate para considerar con mayor detenimiento el tema de la voluntad en Castro; baste con apuntar aquí que el zamorano seńala que ley viene de elegir y no puede haber elección sin libertad, la cual conviene muy poco al intelecto que opera según la naturaleza: Constat autem electionem ad voluntatem pertinere, non ad intellectum: quoniam electio sine libertate esse non potest, quae intellectui minime conuenit, qui secundum naturam operatur. Sobre la voluntad, cfr. Leopoldo José Prieto López, "Suárez sobre el imperium como constitutivo formal de la ley: de Escoto a Kant”, Carthaginensia, XXXVI/70 (2020), pp. 501-526.

${ }^{25}$ Ibid, Lib. $1^{\circ}$, cap. II, p. 31: Nam si aliquid contra legem diuinam lex humana praeciperet aut prohiberet, lex illa nullius esset roboris, nec homines ad illius obseruationem esset astricti. Apuntemos la semejanza entre esta propuesta de Castro y la de Duns Escoto, cfr. Leopoldo José Prieto López, op. cit., p. 504, donde explica que según Escoto la rectitud y justicia de la ley reside en la voluntad humana que se somete a la voluntad divina. 


\section{Algunas proyecciones}

LA FUERZA DE LA LEY RESIDE en que ella es una orden de quien tiene el poder de mandar. Pero, según el teólogo salmantino, todas las leyes vienen, en última instancia, de la voluntad divina: Dios expresa su mandato - por donación de la naturaleza o por revelación directa a los hombres- y el hombre debe obedecer, instituyendo leyes acordes con aquella. Por eso el Decálogo es de ley natural a la vez que de ley divina. Por eso el legislador debe conservar alguna similitud entre los preceptos divinos y las leyes que instituye; por eso no debe prescribir, aunque pueda hacerlo, ninguna ley que sea contraria a los preceptos divinos. La libertad del legislador se hace patente en que puede concretizar un principio general de diversas maneras, eligiendo de entre varias posibilidades la formulación de ley que mejor acomode al caso y las circunstancias; pero solamente podrá haber una ley justa si ésta es acorde con la ley natural-divina.

El papel de la voluntad en la derivación de las leyes se hace más claro cuando el autor habla de quienes desconocen el cristianismo. Castro se empeña en que la ley natural no puede ser desconocida por el hombre, porque está inscrita en su corazón, y ofrece ejemplos de pueblos que prohibían el adulterio y el robo aun sin conocer el Evangelio; pero nada dice sobre los dos primeros preceptos del Decálogo. Como antes apuntamos, el zamorense señala que los romanos no hubieran dispuesto ciertas leyes injustas si hubieran conocido la ley divina e incluso -porque la ignorancia no es pecado, pero rehusarse a conocer lo que estamos obligados a saber sí lo es- señala que el hombre está obligado a hacer cuanto hay en sí mismo para conocer lo que está obligado a saber: la ley divina ${ }^{26}$. La ley natural-divina es imperativa, el hombre debe obedecerla aun sin conocerla, precisamente porque está obligado a conocerla o, por lo menos, a procurar su conocimiento. No se trata de una derivación lógica ni racional, sino de obedecer un principio general que nos gobierna, aunque lo ignoremos, como estamos sujetos a las leyes de nuestra sociedad aunque no podamos dar cuenta de todas y cada una de ellas en particular. Esto se observa cuando Castro habla de América, aprobando la guerra que los reyes católicos llevaron a los pueblos recién descubiertos ${ }^{27}$. Según el autor, la idolatría de los indígenas es una causa justa de guerra, seguramente porque atenta directamente contra el primer precepto del De-

\footnotetext{
${ }^{26}$ Ibid, Lib. $2^{\circ}$, cap. XIV, p. 563: ...quod si is qui ius diuinum ignorat, facit quod in se est, vt illud sciat, vt puta cauendo reliqua peccata \& scientiam sibi necessariam petendo a Deo, tunc Deus illuminabit illum aut interna inspiratione, aut mittendo illi hominem qui illum doceat...

${ }^{27}$ Fratris Alfonsi a Castro Zamorensis, De iusta haereticorum punitione, Salmanticae, Ioannes Giunta, 1547, lib. $2^{\circ}$, cap. 14 , fol. 127 r.
} 
cálogo ${ }^{28}$ o porque, en otras palabras, esas prácticas contradicen la ley divina que toda ley humana debe salvaguardar. No obstante, Castro no condena la ignorancia que los indígenas tienen de la ley divina pues aclara que, antes de hacerles la guerra, debían ser amonestados para que dejaran a sus falsos dioses y veneraran al verdadero Dios. Si los indios se negaran a hacerlo, si además impidieran la predicación del Evangelio, entonces debían ser atacados no sólo porque se oponen a la ley divina con la idolatría, sino porque se resisten a conocer aquello que están obligados a saber: la ley divina.

Asumir de esta manera que la ley divina es superior a las demás, y que a ella deben corresponder las demás, conlleva aceptar valorar toda ley y todo orden social con la ley divina como criterio. Castro no se limita a señalar que los legisladores deben conocer la ley divina para proponer mejores leyes, sino que además mide la justicia de las leyes humanas por la semejanza que tengan con la ley divina, argumenta que la potestad de las leyes nace de esto último e incluso afirma que "los preceptos humanos justos son considerados ser divinos" ${ }^{29}$. En este sentido notemos que su Parecer sobre la educación de los indígenas no diserta en torno a la capacidad racional de los indígenas ${ }^{30}$, sino sobre los conocimientos que éstos requieren para conformar una sociedad cristiana. La argumentación se centra en la necesidad de que los nativos del Nuevo Mundo puedan acceder al estudio del Evangelio, donde se contiene la ley divina ${ }^{31}$. Para él una sociedad más justa es una sociedad cristiana, no importa que esté o no bajo el yugo español -o de cualquier otra nación cristiana-, pues incluso plantea la posibilidad de que "no tolerando la dominación de los españoles, los mismos indios, sin injuria de la fe católica, se sacudan el yugo del rey de España" ${ }^{32}$, en cuyo caso es más que conveniente que se formen doctores entre

\footnotetext{
${ }^{28}$ Castro no dice mucho sobre esto, pero en concordancia con lo antes expuesto, podríamos decir que la idolatría es un atentado contra la ley natural-divina. En cambio, Juan Ginés de Sepúlveda, Tratado sobre las justas causas de la guerra contra los indios, México, FCE, 1996, p. 121-123, es más explícito en establecer que la idolatría es un atentado contra la ley natural: "es lícito a los cristianos perseguir a los paganos y hacerles la guerra si no observan la ley natural como pasa en lo tocante al culto de los ídolos”.

${ }^{29}$ Castro, De potestate, Lib. $1^{\circ}$, cap. IV, p. 56: Praecepta humana iusta censentur esse diuina, \& sic appellantur ab ea, ergo illis, perinde ac diuinis praeceptis erit obediendum, quoniam quae illi recte praecipiunt, a Deo praecepta esse dicuntur.

30 Conocida es la polémica entre Gines de Sepúlveda y Bartolomé de las Casas sobre este tema, para quienes la discusión gira en torno a la capacidad racional de los indígenas para regirse a sí mismos o la necesidad de que alguien más apto los gobierne. Cfr. Juan Álvarez-Cienfuegos, "La polémica de Valladolid entre Sepúlveda y las Casas: similares fundamentos, interpretaciones opuestas", en Memoria del XIII Encuentro Nacional de Investigadores del Pensamiento Novohispano, México, Universidad Autónoma de Aguascalientes, 2001. p. 121-122.

31 Osorio, op. cit., p. 53. Castro argumenta con Pablo: “Todo escrito inspirado por Dios es provechoso para enseñar, para corregir, para enderezar, para educar en la justicia, a fin de que el hombre de Dios esté perfectamente formado y bien provisto para toda clase de obras buenas". Cursivas nuestras.

32 Osorio, op. cit., p. 44. Aunque más adelante, Castro afirma que las Sagradas Escrituras enseñan que debe prestarse la obediencia no sólo a los superiores buenos y modestos sino también a los díscolos.
} 
ellos para que puedan permanecer cristianos. En otras palabras, Castro pone al mismo nivel las leyes de los pueblos siempre que respeten la ley divina, siempre que su ley no estorbe o prohíba la ley divina, siempre que promuevan el conocimiento y la observancia de la ley divina. En el caso de los pueblos gentiles, es la educación en general, y la evangelización en particular, la que los llevará a conocer esa ley divina que deben obedecer, por eso incluso cuando habla de enseñar a los indígenas el latín o las artes liberales lo hace en función de lo que éstos abonan para la inteligencia de las Escrituras y para la observancia del cristianismo.

Bastante de esto podemos encontrar entre los misioneros franciscanos del siglo XVI. También ellos evaluaron las costumbres de los pueblos indígenas en concordancia con sus valores cristianos y consideraron que la moralidad prehispánica, por ejemplo, es acorde con los principios de la ley natural, llegando a decir, como fray Toribio Motolinía (†1569), que "en todo lo que es contra los diez mandamientos de Dios, se tenía [entre los indígenas] ser malo y había leyes e prohibiciones y castigos contra los homicidas y contra los que hurtaban y contra otros vicios y pecados"33, con lo que, como señala Gerónimo de Mendieta (1525-1604), "mucho mejor entendieron ser esto gran verdad, cuando se les predicó, conforme a la ley de Dios" ${ }^{34}$, es decir, que los indígenas aceptaron con facilidad el cristianismo porque sus antiguas leyes y costumbres tenían los mismos principios que las que los misioneros les predicaban, aunque fueran diferentes las leyes indígenas y las españolas: por ejemplo, ambos tenían castigos para el adulterio, aunque entre los nahuas se practicaba la poligamia, ambos imponían castigos para la embriaguez, si bien las leyes indígenas eran más estrictas que las españolas, etc. Los indígenas debían, no obstante, sujetarse a las leyes españolas y, principalmente, sumar el conocimiento del Evangelio a sus buenas leyes y costumbres antiguas; así fray Andrés de Olmos (1485-1571) enseña a los indígenas en su lengua (náhuatl) que deben obedecer la voluntad de Dios y que los pecados más graves son los que apartan de la ley divina, por ejemplo, sobre la avaricia dice que "si no es causando sufrimiento que amontona bienes al enriquecerse, si por ello no ha quebrantado la ley de Dios o aun la ley de la Santa Iglesia, si por ello no ha huido de las cosas divinas tan necesarias, no incurre entonces por ello ni en un pecado pequeño" ${ }^{35}$.

\footnotetext{
33 Fray Toribio Motolinía, Memoriales, libro de las cosas de la Nueva España y de los naturales de ella [ca.1541], México, UNAM, 1971, p. 321.

${ }^{34}$ Fray Gerónimo de Mendieta, Historia eclesiástica indiana, México, CONACULTA, 1997, lib 3º, cap. XLI, p. 442. El capítulo se titula: "De algunas maneras de confesión vocal que los indios tuvieron en su infidelidad, y de cómo les cuadró la confesión sacramental de la Iglesia”.

35 Fray Andrés de Olmos, Tratado sobre los siete pecados mortales (1551-1552), México, UNAM, 1996, p. 67. Por "pecado pequeño" se refiere al pecado venial, según la traducción del náhuatl de G. Baudot. Quisiera destacar
} 
Ya dentro de la sociedad colonial, muchos problemas se evaluaron también en conformidad con la ley divina. Así fray Juan Focher ( $\$ 1572)$ dice sobre el tributo que los jefes indígenas solicitan a sus antiguos súbditos: "sería legalmente injusto, si lo que el súbdito está obligado a pagar se destinara para fomentar la idolatría", pero no siendo así, es justo ya que "la ley divina ordena que los súbditos paguen tributo a sus señores y dicha ley no determina la cantidad concreta, parece que el especificarla se deja al arbitrio de las partes, o sea de los señores y vasallos" ${ }^{36}$. En torno al reconocimiento del matrimonio prehispánico en la nueva sociedad colonial, Focher precisa que si éste "fue contraído en conformidad con sus propias leyes es verdadero contrato matrimonial, I Cor.7, mientras no esté en oposición con alguna ley divina y por más que sea en contra de las leyes de la Iglesia" ${ }^{37}$; es decir que distingue la ley divina de la ley divina positiva y solamente la primera obliga a los indígenas aunque no sean cristianos.

Así pues, damos constancia de una tradición franciscana en el siglo XVI, existente a ambos lados del Atlántico, que entiende la ley como mandato, asume una equivalencia entre la ley natural y la ley divina bajo la forma del Decálogo y para la cual el fundamento último de la potestad de la ley está en la voluntad divina. Todo esto sitúa a la ley divina en el centro a partir del cual se valoran las leyes de otros pueblos, los cuales, como el caso de los nativos americanos, están obligados a ella incluso si la desconocen. Todo esto nos lleva a considerar que los cimientos de las sociedades americanas -antes y después del dominio colonial- son situados, por esta tradición, en la ley divina.

que Olmos, según consigna Gerónimo de Mendieta, tradujo en Nueva España el Adversus omnes haereses de Alfonso de Castro.

${ }^{36}$ Fray Juan Focher, Itinerario del misionero en América, Madrid: Librería General Victoriano Suárez, 1960, part. III, cap. IV, p. 367.

37 Ibid, part. II, cap. XI, p. 244. 


\section{REFERENCIAS BiBLIOGRÁFICAS}

A Castro, Fratris Alfonsi, De potestate legis poenalis libri duo, Lugduni, Haeredes Iacobi Iuntae, MDLVI.

A Castro Fratris Alfonsi, De iusta haereticorum punitione, Salmanticae, Ioannes Giunta, 1547.

Castro, Alfonso de, Si a los hombres del Orbe Nuevo a los que el vulgo llama indios [...] sea conveniente instruirlos en las Artes que llaman Liberales y enseñarles la Sagrada Teología y revelarles todos los Misterios de nuestra Fe [1543], Osorio Romero, Ignacio, La enseñanza del latín a los indios, México, Universidad Nacional Autónoma de México, 1990, pp. 35-60.

Manuel Castro, "Fray Alfonso de Castro OFM (1495-1558), consejero de Carlos V y de Felipe II, Salmanticensis, 6 (1958), pp. 281-322.

https://summa.upsa.es/pdf.vm?id=0000006369\&page=1 \&search=\&lang=es

Contreras Aguirre, Sebastián, "Voluntarism in the early Modern Period? Alphonsus de Castro and his philosophy of law", Acta Philosophica, (2020) 2, pp. 375-394. http://doi.org/10.19272/202000702007

Álvarez-Cienfuegos Fidalgo, Juan, "La polémica de Valladolid entre Sepúlveda y las Casas: similares fundamentos, interpretaciones opuestas", Memoria del XIII Encuentro Nacional de Investigadores del Pensamiento Novohispano, Aguascalientes, Ags., México, Universidad Autónoma de Aguascalientes, 2001, pp. 121-122.

Cruz Cruz, Juan, Cuestiones disputadas del Siglo de Oro, Pamplona, EUNSA, 2009.

Focher, Juan OFM, Itinerario del misionero en América [1574], Madrid, Librería General Victoriano Suárez, 1960.

Lázaro Pulido, Manuel, "Una reflexión sobre la tradición y modernidad en Alfonso de Castro a propósito de la ley", Cauriensia, XIII (2018), pp. 459-478. https://doi.org/10.17398/2340-4256.13.459

Mendieta, Gerónimo de, OFM, Historia eclesiástica indiana, México, CONACULTA, 1997.

Motolinía, Toribio OFM, Memoriales, libro de las cosas de la Nueva España y de los naturales de ella [ca.1541], México, UNAM, 1971.

Olmos, Andrés de, OFM, Tratado sobre los siete pecados mortales (1551-1552), México, UNAM, 1996 [traducción del náhuatl por Georges Baudot]. 
Osorio Romero, Ignacio, La enseñanza del latín a los indios, México, Universidad Nacional Autónoma de México, 1990.

Prieto López, Leopoldo José, "Suárez sobre el imperium como constitutivo formal de la ley: de Escoto a Kant”, Carthaginensia, XXXVI/70, (2020), pp. 501526.

https://revistacarthaginensia.com/index.php/CARTHAGINENSIA/article/ view/158

Sepúlveda, Juan Ginés de, Tratado sobre las justas causas de la guerra contra los indios, México, FCE, 1996.

DOI: https://doi.org/10.15366/bp2021.26.005

Bajo Palabra. II Época. No26. Pgs: 107-122 